\title{
Results of the combined treatment of paediatric intraspinal tumours
}

\author{
F Dincer MD ${ }^{1} \mathrm{C}$ Dincer $\mathrm{MD},{ }^{2} \mathrm{M} \mathrm{K}$ Baskaya $\mathrm{MD}^{3}$ \\ ${ }^{1}$ Associate Professor, Department of Physical Medicine and Rehabilitation, Medical \\ School of Hacettepe University, Ankara, Turkey; ${ }^{2}$ Professor of Neurosurgery, ${ }^{3}$ Resident \\ of Neurosurgery, Department of Neurosurgery, Ibni Sina Hospital, Medical School of \\ Ankara University, Ankara, Turkey.
}

In this article 98 patients with paediatric intraspinal tumours are presented. All were evaluated according to their ages, sex, signs and symptoms. The patients also had radiological and histopathological studies; and the results of surgical, physical medicine and rehabilitation and of radiotherapy are discussed and compared with the results of patients reported in the literature.

Keywords: paediatric intraspinal tumours; rehabilitation; surgery; radiotherapy.

\section{Introduction}

Intraspinal tumours in infants and children present problems in diagnosis that differ from those seen in adults. An alteration of gait and rigidity are early signs of intraspinal tumours in childhood. ${ }^{1,2}$ Although spinal roentgenography and myelography are quite helpful in the diagnosis, computed tomography (CT) and magnetic resonance imaging (MRI) are necessary for detailed information for an accurate diagnosis of these tumours. In addition, ultrasonography is also helpful in the diagnosis, and somatosensorial evoked potentials (SEP) can be used in monitoring the patients. ${ }^{3}$

To obtain the best results with treatment early surgical intervention, radiotherapy and physical medicine and rehabilitation should be instituted together. ${ }^{4-7}$

\section{Material and methods}

This report is based on a review of the clinical records of 98 patients, under 16 years of age, with intraspinal tumours seen between 1967 and 1989.

Of the 98 patients, 48 were boys and 50 girls. This group comprised $7.55 \%$ of all spinal neoplasms operated on in our clinic during the same period. The ratio between spinal tumours of childhood and spinal tumours in general is 1:13.2.

Correspondence: Fitnat Dincer, M.D. Adakale sokak no: 21/15 Kizilay, Ankara, Turkey.
The age distribution curves are interesting. The highest incidence occurred in patients from the eleventh to the end of the sixteenth year of age.

\section{Symptoms}

Pain $92(57.14 \%)$, weakness of one or more limbs and gait disturbance $84(85.71 \%)$ and urinary dysfunction $40(40.81 \%)$ were the most frequent symptoms. Rectal sphincter disturbance in $10(10.20 \%)$ and the presence of a mass and scoliosis were encountered in $4(4.1 \%)$ patients, with torticollis seen in 2 $(2.4 \%)$ patients. The shortest duration of symptoms was 5 days; the longest was 6 years (mean 9.5 months).

\section{Signs}

In all cases the development of clinical signs and symptoms was progressive. The main changes were in reflexes $(85.71 \%)$, paralysis $(73.46 \%)$, and sensory deficits $(69.38 \%)$. Twenty patients $(24.50 \%)$ had paravertebral muscle spasm, $10(10.20 \%)$ showed atrophy, 4 patients $(4.08 \%)$ had kyphoscoliosis, 4 patients $(4.08 \%)$ had scoliosis, 4 patients $(4.08 \%)$ had mass lesions and 2 patients $(2.4 \%)$ had torticollis.

\section{Radiological examination}

The results of spinal roentgenography were available in 90 patients, $62.22 \%$ of whom 
had abnormal findings. Among these findings, there were $16(17.77 \%)$ instances of pedicle erosions, $7(7.77 \%)$ lytic lesions, 11 $(12.22 \%)$ wide spinal canals, $6(6.66 \%)$ wide foramina, $4(4.80 \%)$ scoliosis, 2 $(2.40 \%)$ exostosis and $4(4.80 \%)$ compression fracture. Myelography was performed in 88 patients, and showed a complete block in 74 patients and an incomplete block in 12 . One patient had a normal myelogram: there was a turberculous granuloma at the T6 segment with a mass located posteriorly and intraspinally but with a normal myelogram. A CT scan was obtained in one patient with an osteochondroma, 6 patients with astrocytoma, 2 with lipomas, one with a haemangioma, and one with a meningioma.

MRI was employed in 7 patients, 2 with lipomas, 4 with astrocytomas and one with a haemangioma.

\section{Site}

$8.16 \%$ of the tumours were localised in the cervical spinal canal, $8.16 \%$ in the cervicothoracic, $40.81 \%$ thoracic, $18.36 \%$ thoracolumbar, $22.44 \%$ lumbar and only 2 tumours were situated in the lumbosacral region. Twenty-six tumours were intramedullary, 16 intradural-extramedullary, 52 epidural and 4 tumours were dumbbell.

\section{Treatment}

All 98 patients were treated surgically, by laminectomy. Twenty-six received radiotherapy postoperatively. We did not use microsurgery and, when indicated, avoided total excision even for some nonmalignant neoplasms because of the possibility of aggravating the lesion of the spinal cord. Total excision was possible in $59(60.24 \%)$ patients, and this included 8 patients with astrocytomas, 2 with ependymomas, 10 with neurofibromas, 2 with menengiomas, 8 with congenital tumours, 4 with tuberculous granulomas, and 2 patients with lymphoid tumours.

Subtotal excision was performed in 38 $(39.76 \%)$ patients, including 4 with a thoracic astrocytoma, 2 with a hydatid cyst, and 2 patients had unverified tumours. The extradural localised tumours in whom subtotal excisions were performed were: 14 osteogenic, 6 lymphoid, 2 congenital, 6 metastasis, and 2 fibroadipose tissue. Biopsy alone was made in a T2-T9 localised astrocytoma case following decompressive laminectomy. Total removal was achieved in $80.7 \%$ of intramedullary tumours, $75 \%$ of intradural extramedullary tumours, $50 \%$ of dumbbell tumours and in $46.1 \%$ of epidural tumours (Table I).

\section{Histology}

Histological diagnosis was available in 96 of the spinal tumours. To simplify discussion, the tumours have been classified into four major categories: congenital, primary, osteogenic, and others (Table II).

1 Primary spinal tumours (28 cases) include astrocytomas (14), neurofibromas (10), meningiomas (2), and ependymomas (2).

Table I Site and treatment

\begin{tabular}{lcccc}
\hline Site & TE & STE & B & Total \\
\hline Intramedullary & 21 & 4 & 1 & 26 \\
& $(80.73 \%)$ & $(15.38 \%)$ & $(3.84 \%)$ & 16 \\
Intradural & 12 & 4 & - & 52 \\
(extramedullary) & $(75.0 \%)$ & $(25.0 \%)$ & 28 & \\
Epidural & 24 & $(53.84 \%)$ & & 4 \\
& $(46.16 \%)$ & 2 & - & 98 \\
Dumbbell & 2 & $(50.0 \%)$ & 1 & \\
Total & $(50.0 \%)$ & 38 & $(1.0 \%)$ & \\
& $59(60.24 \%)$ & $(38.76 \%)$ & & \\
\hline
\end{tabular}

$\mathrm{TE}=$ total excision; $\mathrm{STE}=$ subtotal excision; $\mathrm{B}=$ biopsy. 
Table II Histopathological type of tumours

\begin{tabular}{lrc}
\hline Type of tumour & \multicolumn{2}{c}{ No } \\
\hline Primary spinal tumours & $28(28.57 \%)$ \\
Astrocytoma & 14 & $(14.28 \%)$ \\
Meningioma & 2 & $(2.04 \%)$ \\
Neurofibroma & 10 & $(10.20 \%)$ \\
Ependymoma & 2 & $(2.04 \%)$ \\
Congenital tumours & 20 & $(20.4 \%)$ \\
Epidermoid & 10 & $(10.20 \%)$ \\
Lipoma & 4 & $(4.08 \%)$ \\
Arachnoid cyst & 4 & $(4.08 \%)$ \\
Teratoma & 2 & $(2.04 \%)$ \\
Bone tumours & 22 & $(22.44 \%)$ \\
Haemangioma & 6 & $(6.12 \%)$ \\
Aneurysmal bone cyst & 4 & $(4.08 \%)$ \\
Endothelial myeloma & 4 & $(4.08 \%)$ \\
Immunoblastic sarcoma & 2 & $(2.04 \%)$ \\
Osteoma & 2 & $(2.04 \%)$ \\
Osteochondroma & 2 & $(2.04 \%)$ \\
End. Myelom-E. sarcoma & 2 & $(2.04 \%)$ \\
Lymphoid tumours & 8 & $(8.16 \%)$ \\
Lymphosarcoma & 2 & $(2.04 \%)$ \\
Lymphoblastic lymphoma & 2 & $(2.04 \%)$ \\
Burkitt lymphoma & 2 & $(2.04 \%)$ \\
Malignant lymphoma & 2 & $(2.04 \%)$ \\
Infections-parasites & 6 & $(6.12 \%)$ \\
Cyst hydatid & 2 & $(2.04 \%)$ \\
Tuberculous granulation tissue & 4 & $(4.08 \%)$ \\
Miscellaneous & 14 & $(14.36 \%)$ \\
Metastasis & 6 & $(6.12 \%)$ \\
Ossified fibroma & 2 & $(2.04 \%)$ \\
Fibroadipose tumour & 2 & $(2.04 \%)$ \\
Non verified & 4 & $(4.08 \%)$ \\
\hline & & \\
\hline & &
\end{tabular}

2 Congenital tumours (20) include epidermoids (10), arachnoid cysts (4), and teratomas (2).

3 Osteogenic tumours (22) include endothelial myelomas (EM) (4), EM plus Ewing sarcoma (2), osteomas (2), haemangiomas (6), aneurysmal bone cysts (4), and immunoblastic sarcomas (2).

4 Other tumours include those of lymphoid origin (8), parasitic and infectious pathologies (6), metastases (6), ossified fibromas (2), fibroadipose masses (2), and non verified tumours (4).

\section{Pathology and location}

1 Intramedullary (IM): of 26 patients 14 had astrocytomas, 8 had epidermoids, 2 had ependymomas, and 2 had turberculous granulomas.

2 Intradural (ID): of 16 patients; 6 had neurofibromas, 2 had meningiomas, 2 had epidermoids, 2 had arachnoid cysts, 2 had hydatid cysts and 2 had non verified lesions.

3 Extradural (ED): of 56 patients 6 had metastatic tumours, 6 had haemangiomas, 4 had neurofibromas, 4 had aneurysmal bone cysts, 4 had endothelial myelomas, 2 had lipomas, 2 had arachnoid cysts, 2 had teratomas, 2 had EM plus Ewing's sarcomas, 2 had osteomas, 2 had osteochondromas, 2 had immunoblastic sarcomas, 2 had lymphosarcomas, 2 had lymphoblastic lymphomas, 2 had malignant lymphomas, 2 had tuberculous granulomas, 2 
had ossified fibromas, and 2 had non verified lesions. Additionally 2 patients had fibroadipose masses and 2 patients had lipomas all in the dumbbell position.

\section{Results}

All patients in this series have been followed up for a minimum period of one month, and many have been followed for 15 months. The outcome was classified as markedly good (MG), slightly good (SG), unchanged (NC) and poor (P). (a) A markedly good result is where there is no evidence of clinical or radiological recurrence of the initial disease at follow up, and the patient is neurologically intact. (b) A slightly good result is where there is no evidence of recurrence of the initial problem but there is a degree of persistent neurological deficit. (c) A 'no change' result implies persistence of a neurological deficit and evidence of the presence of the original disease. (d) A poor result is non improvement or progression of the initial disease with a major neurological deficit.

A markedly good result was obtained in 24 patients $(13.48 \%)$ and slightly good in 52 $(53.06 \%)$ cases. In $14(14.28 \%)$ patients no change was seen, and in $6(6.12 \%)$ patients the result was poor. Two patients died $(2 \%)$. In the follow up period 2 patients died after one month from metastatic tumours (one with a Wilm's tumour, and another patient with a rhabdomyosarcoma). After the first month following the operation, 6 patients were fairly well (SG), 6 showed no change (NC) and 2 patients were in a poor condition $(\mathrm{P})$ in the astrocytoma group. Nine total excisions $(\mathrm{T}), 4$ subtotal excision (ST) and 1 biopsy were performed in this same group. Two patients who had ependymomas and underwent total excision operations were in a markedly good condition (MG). Ten patients with neurofibromas and 2 with meningiomas had the neoplasm totally removed. All the meningioma patients and 6 of the neurofibroma patients were in markedly good condition whereas the remaining 4 neurofibroma patients were in fairly good condition. Among the 20 patients with congenital tumours, 18 total excision operations were performed. In the follow up period, half of these patients were in a markedly good condition and the other half in a fairly good condition. There were 22 osteogenic tumours, 8 being totally excised and 14 subtotal excisions were performed. Four of these patients were in markedly good condition, 14 were in a poor condition. Among the 8 lymphoid tumours 2 total excision operations were performed and in the follow up 4 of these patients were in fairly good condition whereas the other 4 showed no change. There were 6 metastatic tumours in which subtotal excision operations were perfomed. Later, 2 of these patients were in a fairly good condition, 2 showed no change and 2 were in a poor condition. Six patients had tuberculous granulomas and hydatid cysts, and in the 4 patients with tuberculous granulomas total excision operations were performed. The treatment for the patients with multilocular hydatid cysts consisted of subtotal excision following injection of $1 \%$ iodine solution. All the 6 patients in this group were in fairly good condition at follow up one month later. The 2 patients with fibromas and another 2 patients with fibroadipose tissue who had undergone total excision operations were all in fairly good condition.

In the fifteenth postoperative month, our patients presented as follows. In the intramedullary tumours group, patients were neurologically stabilised and showed no important changes in their clinical conditions. As above, the patients with meningioma excision operations were in the same clinical condition. Eight of the 10 neurofibroma patients were in markedly good condition.

Among the 20 patients with congenital tumours, 14 were in a markedly good condition, whereas the other 6 patients were in a fairly good condition.

In the osteogenic tumours group, one patient with immunoblastic sarcoma died.

\section{Postoperative complications}

Twenty-five patients $(34.72 \%)$ had kyphoscoliosis, $5(6.9 \%)$ had paralytic dislocation of the hips, $9(12.50 \%)$ had leg length discrepancy and 33 patients $(45.83 \%)$ had 
contractures and deformities of their lower extremities. These 72 patients had the above listed postoperative problems in varying degrees (Table III).

\section{Rehabilitation}

Patients in group (a) had no rehabilitation $(24.48 \%)$. However the other patients had intensive physiotherapy including active, passive, active resistive exercises, strengthening exercises and gait and bladder training.

The 52 patients in group (b) were successfully rehabilitated $(53.06 \%)$, and they were able to walk independently and carry out daily activities on their own.

Intensive physiotherapy was instituted for patients in groups (c) and (d). The group (c) patients $(14.28 \%)$ were also successfully rehabilitated and became functional ambulatories. Ten $(13.88 \%)$ in groups (b) and (c) wore spinal braces, $17(23.61 \%)$ spinal braces and long leg walking braces, 27 $(37.50 \%)$ long leg walking braces with pelvic band, and $12(16.66 \%)$ walked with long leg walking braces. The result of rehabilitation in group (d) were poor. We were not very successful in the rehabilitation of these patients, who were wheelchair bound and could not walk. (Table III).

\section{Discussion}

The child with an intraspinal tumour usually presents with weakness of one or more extremity $(85.71 \%$ of our patients), pain $(57.14 \%)$ or sphincter dysfunction $(40.81 \%)$. Pain is the most common and also the most important symptom. Its importance is due to the fact that it enables early diagnosis.

Extremity and back pains are the most frequent symptoms in the recently published series. ${ }^{8-11}$ In our series, extremity weakness is more common $(85.71 \%)$ with respect to reports in other series. Urinary dysfunction which was reported to be $8 \%, 22.5 \%$, and $30 \%$ in the literature was $40.81 \%$ in our series. ${ }^{2,9,12}$ The interesting point is that this dysfunction occurs in $28.57 \%$ postoperatively. ${ }^{13}$

Scoliosis occurred in $4.8 \%$ of our series. In our series, the symptoms were generally met with more frequently and in a greater variety. Could this be related to delayed diagnosis?

Richardson emphasised the importance of spinal rigidity as an early sign of intraspinal tumour. ${ }^{14}$ An alteration of gait was the most frequent symptom in these patients and should be stressed as a pertinent finding. ${ }^{15}$

The percentages of the clinical symptoms and signs in our series approximately match

Table III Postoperative problems requiring rehabilitative follow up

\begin{tabular}{|c|c|c|c|c|c|}
\hline & KYP & $\mathrm{PDH}$ & LLD & $C \& D L E$ & Total \\
\hline Wheelchair & $\begin{array}{l}3 \\
4.1 \%\end{array}$ & - & - & $\begin{array}{l}3 \\
4.1 \%\end{array}$ & $\begin{array}{l}6 \\
8.33 \%\end{array}$ \\
\hline Spinal brace & $\begin{array}{c}9 \\
12.5 \%\end{array}$ & $\begin{array}{l}1 \\
1.3 \%\end{array}$ & - & - & $\begin{array}{l}10 \\
13.88 \%\end{array}$ \\
\hline $\begin{array}{l}\text { Spinal brace } \\
\text { and long leg } \\
\text { walking brace }\end{array}$ & $\begin{array}{l}13 \\
18.05 \%\end{array}$ & $\begin{array}{l}1 \\
1.3 \%\end{array}$ & - & $\begin{array}{l}3 \\
4.1 \%\end{array}$ & $\begin{array}{l}17 \\
23.61 \%\end{array}$ \\
\hline Long leg walking & & & & & \\
\hline $\begin{array}{l}\text { brace with pelvic } \\
\text { band }\end{array}$ & - & $\begin{array}{l}3 \\
4.1 \%\end{array}$ & $\begin{array}{l}3 \\
4.1 \%\end{array}$ & $\begin{array}{l}21 \\
29.6 \%\end{array}$ & $\begin{array}{l}27 \\
37.5 \%\end{array}$ \\
\hline $\begin{array}{l}\text { Long leg } \\
\text { walking brace }\end{array}$ & - & - & $\begin{array}{l}6 \\
8.3 \%\end{array}$ & $\begin{array}{l}6 \\
8.3 \%\end{array}$ & $\begin{array}{l}12 \\
16.16 \%\end{array}$ \\
\hline Total & $\begin{array}{l}25 \\
34.72 \%\end{array}$ & $\begin{array}{l}5 \\
6.9 \%\end{array}$ & $\begin{array}{l}9 \\
12.5 \%\end{array}$ & $\begin{array}{l}33 \\
45.83 \%\end{array}$ & $\begin{array}{c}72 \\
100 \%\end{array}$ \\
\hline
\end{tabular}

KYS = Kyphoscoliosis; PDH = Paralytic dislocation of hips; LLD = Leg length discrepancy; $\mathrm{C} \& \mathrm{DLE}=$ Contractures and deformitities of lower extremities. 
those reported in the literature..$^{2,9-12}$ In approximately $15 \%$ of the patients, pain continued after the operations. However various neurological defects were cured postoperatively after an interval of 12 months. The incidence of kyphoscoliosis was $25.51 \%$ in our series (Table III). Accordingly we suggest that in patient follow up after spinal cord tumour surgery, immediate spinal brace application should be employed.

The types of tumour in our series and in the others are shown in Tables IV and V.

We agree with Matson that much of the residual disability which occurs results from prolonged delay before a proper diagnosis is made, rather than from the effects of the operation or from progression of the disease postoperatively. ${ }^{15}$ In our series, $73.46 \%$ of the patients had paralysis when first seen.
In our series, the localisation frequencies according to segmental classification is: thoracic $(40.8 \%)$, lumbar $(22.4 \%)$, thoracolumbar $(18.3 \%)$.

Cooper and Epstein ${ }^{16}$ reported that, among children, intramedullary tumours are seen in the cervical and cervicothoracic regions in the ratio of $46 \%$. Di Lorenzo ${ }^{17}$ reported in 1979 on 1234 cases which he formed by adding his own series to the patients he found in the literature, and he stated that sarcoma and congenital tumours were the next two most frequent tumours after glial tumours. Metastatic tumours occupied the fourth place in frequency. In our study the frequency was different: bone tumours, congenital tumours and glial tumours. In our series there were 4 intraspinal tuberculomas (2 intramedullary, 2 extradurally), whereas in the literature, only De

Table IV Histopathological type of the tumours in literature ${ }^{17}$ and in our series

\begin{tabular}{lrrrrrr}
\hline Author & Glial & M & N & C & Other & Total \\
\hline Hamby, 1944 & 44 & 10 & 23 & 11 & 60 & 185 \\
Ford, 1952 & 5 & - & 2 & 1 & 11 & 19 \\
Ross, 1953 & 5 & 1 & - & 3 & 4 & 13 \\
Dodge, 1956 & 25 & - & 10 & 3 & 14 & 52 \\
Grant, 1956 & 7 & 5 & 3 & - & 8 & 23 \\
Nittner, 1956 & 11 & 2 & 5 & - & 8 & 26 \\
Haft, 1959 & 9 & 1 & 2 & 4 & 13 & 30 \\
Klein, 1960 & 6 & 1 & 1 & 8 & 19 & 35 \\
Rand, 1960 & 20 & 2 & 5 & 5 & 17 & 48 \\
Coxe, 1961 & 15 & - & 3 & 13 & 11 & 42 \\
Dereymaeker, 1962 & 5 & - & - & 4 & 4 & 13 \\
Iraci, 1966 & 13 & 1 & - & 1 & 4 & 19 \\
Arseni, 1967 & 11 & 2 & 7 & 5 & 10 & 35 \\
Matson, 1969 & 30 & 3 & 6 & 34 & 49 & 122 \\
Banna, 1971 & 9 & - & 2 & - & 12 & 23 \\
Intrau, 1971 & 1 & 2 & 4 & 1 & 2 & 10 \\
Friedman, 1972 & 18 & 2 & 6 & 9 & 11 & 46 \\
Koos, 1973 & 21 & 3 & 10 & 12 & 27 & 73 \\
Rougerie, 1973 & 18 & 3 & 5 & 5 & 27 & 58 \\
Grote, 1975 & 21 & 2 & 11 & 25 & 24 & 83 \\
Till, 1975 & 6 & 2 & 6 & 5 & 25 & 43 \\
Hutteroth, 1976 & 2 & - & - & 1 & 12 & 15 \\
Kordas, 1977 & 14 & - & 6 & 17 & 29 & 66 \\
Farwel, 1977-78 & 26 & 1 & - & 2 & -17 & 29 \\
De Sousa, 1979 & 19 & 3 & 9 & 22 & 70 \\
Di Lorenzo, 1982 & 11 & - & 4 & 7 & 34 & 56 \\
OUR, 1990 & 16 & 2 & 10 & 20 & 50 & 98 \\
Total & 358 & 48 & 135 & 215 & 501 & 1332 \\
Percent (\%) & 30.69 & 3.35 & 10.1 & 15.97 & 37.1 & 100.00 \\
\hline & & & & & \\
M & 16 & & & &
\end{tabular}

$\mathrm{M}=$ meningioma $; \mathrm{N}=$ neurofibroma $\mathrm{C}=$ congenital. 
Table V Relationship between tumours and cord site in our series and in literature

\begin{tabular}{lrrrrr}
\hline Author & ED & ID & DB & IM & Total \\
\hline Hamby, 1935 & 43 & 23 & 5 & 29 & 100 \\
Hamby, 1944 & 42 & 37 & 1 & 30 & 110 \\
Ford, 1952 & 11 & 4 & - & 4 & 19 \\
Grant, 1956 & 8 & 10 & - & 6 & 24 \\
Nittner, 1956 & 8 & 7 & - & 11 & 26 \\
Haft, 1959 & 15 & 5 & - & 10 & 30 \\
Rand, 1960 & 19 & 8 & 1 & 20 & 48 \\
Dereymaeker, 1962 & 5 & 4 & - & 4 & 13 \\
Iraci, 1966 & 5 & 1 & - & 13 & 19 \\
Arseni, 1967 & 12 & 14 & - & 16 & 42 \\
Banna, 1971 & 12 & 2 & - & 9 & 23 \\
Inrau, 1971 & 2 & 7 & 1 & 10 & 20 \\
Grote, 1975 & 49 & 13 & - & 21 & 83 \\
Hutteroth, 1976 & 13 & - & - & 2 & 15 \\
Kordas, 1977 & 32 & 20 & - & 28 & 80 \\
De Sousa, 1979 & 29 & 28 & - & 24 & 81 \\
Di Lorenzo, 1979 & 35 & 10 & - & 11 & 56 \\
OUR, 1990 & 48 & 18 & 4 & 24 & 98 \\
Total & 388 & 211 & 12 & 277 & 897 \\
Percent (\%) & 43.0 & 24.4 & 1.0 & 31.4 & 99.9 \\
\hline
\end{tabular}

$\mathrm{ED}=$ epidural; $\mathrm{ID}=$ intradural; $\mathrm{DB}=$ dumbbell; $\mathrm{IM}=$ intramedullary.

Sousa reported one case. Similarly we had 2 intraspinal multilocular hydatid cyst cases, a condition not reported in other series. Lymphoid tumours have an incidence of $1-3 \%$ in other series whereas they are more frequently $(8.16 \%)$ encountered in our series. ${ }^{2,10-12,17}$

Spinal roentgenography was abnormal in $62.22 \%$ of our patients. Matson ${ }^{15}$ found abnormal spine radiography in $66 \%$ of his patients. Ekelund has stressed the importance of dorsal excavation and pedicle erosion of the vertebral bodies in the diagnosis. ${ }^{3}$ Myelography demonstrated the lesion in $97.06 \%$ of the our patients. De Sousa ${ }^{9}$ found an abnormal myelogram in 67 of 70 patients.

We diagnosed one spinal neoplasm using CT. CT with metrizamide can show cystic cavities above and below the area of solid tumour in delayed scans while adjacent areas of solid tumour appeared as widened spinal cord, but do not fill with metrizamide.

Twelve of our patients who all had CT, also underwent myelography except for one with osteochondroma. Ninety percent of astrocytomas show blocks in their immediate or delayed CT scans if they are focal. It is easy to define lipomas as intraspinal low density masses with CT scans. On the other hand meningiomas can be defined by CT scans by erosive changes which do not accompany periosteal reactions. ${ }^{18}$ Haemangiomas show mild to moderate hyperdensities together with possible calcification. ${ }^{18}$ For these two types of tumours MR images are nonspecific. ${ }^{18}$ Astrocytomas appear as cystic tumours in MR images in $38 \%$ of the cases. ${ }^{19}$ This rate rises to as high as $45 \%$ in ependymomas. It should be acknowledged that MRI is a vital diagnostic tool for determining the neoplastic nature of the intraspinal cysts. ${ }^{14,20}$

Blews, ${ }^{21}$ who investigated spinal intradural metastatic masses in a paediatric population, considers that MRI is equally or more valuable than myelography or CT imaging for the diagnosis of these lesions. MRI, in spinal tumours, can accurately localise spinal canal widening without the need for the introduction of contrast media into the subarachnoid space. ${ }^{20}$

Transcutaneous ultrasonography may be 
more informative than conventional myelography or metrizamide spine CT scanning, as it gives a direct view of the interior of the spinal cord. This method is reported to be a most valuable and reliable diagnostic tool in determining the nature and extent of tumours in early childhood. ${ }^{22}$ By means of intraoperative ultrasonography, cystic or solid components of spinal tumours are established and the superior and inferior contours are better identified and localised by this method than by $\mathrm{CT} .{ }^{23}$ Apart from this, the intraoperative use of ultrasound shows the optimal area where the dura can be opened and myelotomy performed.

Somatosensory evoked potentials (SSEP) are used for monitoring intraspinal sensory pathways. This monitoring is only valuable if the information is immediately available and utilised by the surgeon to modify the operative dissection. Postoperative monitoring provides less information than does clinical observation for determining the presence of a haematoma. ${ }^{24}$ By the use of cauda equina stimulation technique, waves with at least double amplitudes can be recorded. ${ }^{25}$ More sensitive SSEP recordings can be performed by this technique. When used in conjunction with lasers, SSEP monitoring provides time for the surgeon to stop and cool the tissue by irrigation. ${ }^{10,26}$

We performed SSEP monitoring in 12 of our patients and in 7 of these patients, findings closely correlated with the clinical condition were obtained.

The treatment of all the intraspinal tumours in our children was surgical. A total removal was possible in over one third of De Sousa's patients $(57.14 \%$ in our series). As would be expected, patients in whom total removal could be performed had a better chance of complete recovery, indicating a better prognosis for patients diagnosed and treated early. We removed astrocytomas totally in $75 \%$ of patients. During the spinal cord tumour operations and especially during the operations performed on intramedullary tumours, the use of bipolar coagulation-dissecting microscope, CUSA, and lasers (CO2, Argon, Nd:YAG) helped the surgeon greatly in total excision of the tumour. During operations for astrocytomas, as there is no definite tumour- spinal cord cleavage plane, CUSA enabled us to excise the tumour without cord manipulation and trauma.

$\mathrm{CO} 2$ laser provides the vaporisation of solid tumours and removal of the residual tumour after the use of CUSA. Argon laser is usually less traumatic and often more haemostatic being used for the excision of strategically placed, small, and moderately vascular spinal cord tumours. Nd:YAG laser can be used in the vicinity of the spinal cord and brain stem with the help of SEP. ${ }^{26}$

Radiotherapy was given for cluster with astrocytomas. De Sousa suggested that a child with an intramedullary astrocytoma should have a decompressive laminectomy with biopsy and/or myelotomy. ${ }^{9}$ Radiation therapy is definitely effective in the case of ependymomas but data radiation therapy for spinal cord astrocytomas is difficult to interpret. If there is a malignant astrocytoma he advises total neuraxis radiation because radical surgery has not yet significantly improved prognosis. ${ }^{10}$ Five percent of the children with solid malignant tumours develop spinal cord compression during the course of their disease. Klein ${ }^{11}$ found no statistical difference in the degree of neurological improvement between his operative and nonoperative treatment groups in patients with small cell tumours (neuroblastoma, Hodgkin's and Germ cell tumours). Patients with spinal cord compression from metastatic sarcoma (Ewing's sarcoma, osteogenic sarcoma, soft tissue sarcoma and rhabdomyosarcoma) showed a significant improvement with decompressive laminectomy alone or before medical therapy, compared to those who received radiation therapy and/or chemotherapy without surgery in Klein's study. Raffel stated that epidural malignancy in a child is often identified before significant spinal canal compromise has occurred and that these children can frequently be managed by radiation therapy and/or chemotherapy. ${ }^{12}$ He compared the results of surgery followed by adjuvant therapy with the results obtained without surgery. His results indicated that these children are best treated by a combination of surgical decompression and tumour removal followed by adjuvant therapy regardless of the tumour type. ${ }^{12}$ For 
similar cases our management protocol included radiotherapy and/or chemotherapy to all patients following surgical decompression and maximal tumour removal.

In our 24 epidural malignancy patients with various histopathologies 2 patients died in the fifteenth month. In the postoperative sixth month the number of ambulatory patients increased from 11 to 16 , and correspondingly the number of nonambulatory patients decreased from 10 to 6 and also the number of paraplegic patients decreased from 3 to 2 .

Progress in the field of medical oncology enables us to attain quick responses and regressions in the treatment of small-cell tumours by new therapeutic regimens. These regimens are put forward as an alternative to laminectomy and/or radiation therapy. Hayer ${ }^{27}$ has succeeded in keeping 12 patients (out of his 14 neuroblastoma and Ewing's sarcoma patients) neurologically intact with chemotherapy alone.

We were unable to compare the results of our series with other such series because we had performed surgery in all of our patients and had given radiation therapy to most of them. However we strongly believe and recommend the use of surgical treatment, especially in patients with advanced encroachment into the spinal canal or with tumours localised in the narrow segments of the spinal canal when the general health condition of the patient is suitable for operation. Appropriate and early rehabilitation is as important as surgery and radiotherapy in the treatment of paediatric intraspinal tumours.

For diagnosis and treatment of postoperative problems in children undergoing spinal surgery, close follow up is essential. Bone destruction, extensive laminectomy, muscle paralysis of the trunk and the hips, fascial contractures, gravity and radiotherapy can present postoperative problems. Deformities may develop in patients with multilevel laminectomies who have not received radiation therapy, especially in the cervical $(100 \%)$ and thoracic $(36 \%)$ regions. Yasuoka et al reported these percentages for periods of rapid growth. ${ }^{28}$ There are also reported cases of deformities caused by asymmetric irradiation. ${ }^{11,29,30}$ The pro- cedure of laminotomy described by Raimondi ${ }^{31}$ which we performed in many of our patients may partially prevent these complications. The appropriate conservative preventive postoperative measures taken in these patients decreased the incidence of deformities and therefore the number of patients requiring stabilisation operation. ${ }^{13,32}$ There were no patients with deformities in Epstein's series, because all his patients wore a brace for 2 years. ${ }^{32}$ By the early application of rehabilitative measures our patients, to date, have not required fusion operations. The indications for the stabilisation operation include pain and the presence of neurological deficits. If there is localised kyphosis and/or segmental instability following radiotherapy, ie if there is pain which disappears with rest and appears with movements, and MR images show segmental stabilisation, then the necessity for a stabilisation operation is considered. However the absence of tumour in the spinal canal should be demonstrated by myelography before the operation.

Recently successful methods have become available for the treatment of spasticity, which can be a great problem in some patients. Hertz ${ }^{33}$ has reported a success rate of $95 \%$ in 118 patients with foraminal rhizotomy using percutaneous frequency, in whom medical therapy was unsuccessful.

\section{Conclusion}

It is almost impossible to lessen the neurological deficits caused by spinal cord compression in adult patients in spite of every effort and treatment. But in the case of children, in spite of total motor and sensory deficit the patient has a $50 \%$ chance of being ambulatory. Due to the above mentioned reasons, the combined usage of early diagnostic methods, together with radical surgery and medical therapy modalities becomes much more important. ECHO, CT, myelography, and MRI give very valuable information for the diagnosis and follow up and also enable the surgeon to perform operations. Microsurgery, CUSA, lasers, and SEP offer the surgeon great advantages and lower the incidence of postoperative complications. 
Chemotherapy and/or radiation therapy should always be employed in cases with such therapy requirements. During the follow up of these patients MRI should always be used. It is also essential to take prevent- ive PMR measures for patients with spinal stabilisation problems. Preventive PMR measures when taken properly may avoid the need for stabilisation operations.

\section{References}

1 Arseni C, Horvath L, Iliescu D (1967) Intraspinal tumour in children. Psychiat Neurol Neurochir 70: 123-133.

2 Farwel JR, Dohrmann J (1977-78) Intraspinal neoplasm in children. Paraplegia 15: 262-273.

3 Ekelund L, Cronqvist S (1973) Roentgenological changes in spinal malformation and spinal tumours in children. Radiologie 13: 541-546.

4 Banna M, Gryspeerdt L (1971) Intraspinal tumour in children. Clin Radiol 22: 17-32.

5 Epstein F (1986) Spinal cord astrocytomas of childhood (1986) In: Symon L, editor. Advances and Technical Standards in Neurosurgery. Springer Verlag, Wien, New York: 135-169.

6 Hendrick EB (1982) Spinal cord tumours in children. In: Youmans JR, editor. Neurological Surgery. 2nd ed. W B Saunders, Philadelphia: vol 4, 3215-3222.

7 Hoffman HJ, Griebel RW, Hendrick EB (1986) Congenital spinal cord tumours in children. In: Symon L, editor. Advances and Technical Standards in Neurosurgery. Springer Verlag, Wien, New York: 175-200.

8 Sun HY and McLone DG (1984) Pain in children with spinal cord tumours. Child Brain 11: 36-46.

9 De Sousa A, Kalsbeek J, Mealey J, Campbell RL, Hockey A (1979) Intraspinal tumours in children. A review of 81 cases. J Neurosurg 51: 437-445.

10 Epstein F and Wisoff JH (1989) Intramedullary tumours of the spinal cord. In: Wonsiewicz M, editor. Pediatric Neurosurgery. Surgery of the Developing Nervous System. 2nd ed. W B Saunders, Philadelphia: 428-442.

11 Klein DM (1989) Extramedullary spinal tumours. In: Wonsiewicz M, editor. Pediatric Neurosurgery. Surgery of the Developing Nervous System. 2nd ed. W B Saunders, Philadelphia: 443-452.

12 Raffel C, Neave VC, Lavine S, McComb JG (1991) Treatment of spinal cord compression by epidural malignancy in childhood. Neurosurgery 28: 349-356.

13 Iraci G (1966) Intraspinal tumours of infancy and childhood. J Pediatr Surg 1966 1: 534-545.

14 Richardson F (1960) A report of 16 tumours of the spinal cord in children. J Pediatr 57: 42-54.

15 Matson D, Tachdjian P (1963) Intraspinal tumours in infants and children. Postgrad Med 34: 279-285.

16 Cooper PR, Epstein F (1985) Radical resection of intramedullary spinal cord tumours in adults. $J$ Neurosurg 63: 492-499.

17 Di Lorenzo, Giuffre R, Fortuna A (1982) Primary spinal neoplasm in childhood. Neurochirurgia 25: 153-164.

18 Pomeranz SJ (1989) Neoplasms of the spine. In: Pomeranz SJ, editor. Craniospinal Magnetic Resonance Imaging. W B Saunders, Philadelphia: 513-543.

19 Duthoy MJ and Lund G (1988) MR imaging of the spine in children. Eur J Radiol 8: 188-195.

20 Fredericks BJ (1989) Diseases of the spinal canal in children: diagnosis with noncontrast CT scans. AJNR 10: $1233-1238$.

21 Blews DE, Wano H, Kumar AJ, Robb PA, Phillips PC, Bryan RN (1990) Intradural spinal metastases in pediatric patients with primary intracranial neoplasms: Gd-DTPA enhanced MR vs CT myelography. $J$ Comput Assist Tomogr 14: 730-735.

22 Zieger M, Dorr U, Schluze I (1988) Pediatric spinal sonography. Part II: Malformations and mass lesions. Pediatr Radiol 18: 105-111.

23 Grundy BL (1987) Monitoring of SEP during neurosurgical operations: Methods and applications. Neurosurgery 20: $169-182$.

24 Lueders H, Hahn J, Gurd A (1982) Surgical monitoring of spinal cord function: Cauda Equina stimulation technique. Neurosurgery 11: 482-485.

25 Long RR and Wirth F (1987) Reversible SEP changes with Nd:YAG laser use. Neurosurgery 21: $465-467$.

26 Levy WJ (1987) Clinical experience with motor and cerebellar evoked potential monitoring. Neurosurgery 20: $169-182$.

27 Hayer FA, Thompson EI, Hvizdala G (1984) Chemotherapy as an alternative to laminectomy and radiation in the management of epidural tumour. J Pediatr 104: 221-224.

28 Yasuoka S, Peterson HA, MacCarty CS (1982) Incidence of spinal column deformity after multilevel laminectomy in children and adults. J Neurosurg 57: 441-445.

29 Fisher GG, Hall JG (1982) Spinal deformities following neurosurgical procedure in children. In: Schmidek $\mathrm{HH}$, Sweet WH, editors. Operative Neurosurgical Technics. Indications, Methods and Results. Grune \& Stratton, New York: vol 1, 63-69.

30 Mayfield JK et al (1981) Spinal deformity in children treated for neuroblastoma. The effect of radiation and other forms of treatment. J Bone Joint Surg 63(A): 188-193. 
31 Raimondi AJ (1978) Reflection of a laminar flap for exposure of the spinal canal in children. Clin Neurosurg 25: 504-511.

32 Epstein F and Epstein W (1982) Surgical treatment of spinal cord astrocytomas of childhood. J Neurosurg 57: 685-689.

33 Herz DA, Looman JE, Tiberio A (1990) The management of paralytic spasticity. Neurosurgery 26: 300-306. 